\title{
Pipecolic Acid Is Induced in Barley upon Infection and Triggers Immune Responses Associated with Elevated Nitric Oxide Accumulation
}

\author{
Miriam Lenk, Marion Wenig, Kornelia Bauer, Florian Hug, Claudia Knappe, Birgit Lange, Timsy, \\ Finni Häußler, Felicitas Mengel, Sanjukta Dey, Anton Schäffner, and A. Corina Vlot ${ }^{\dagger}$
}

\author{
Helmholtz Zentrum München, Department of Environmental Science, Institute of Biochemical Plant Pathology, Ingolstädter \\ Landstr. 1, 85764 Neuherberg, Germany
}

Accepted 11 June 2019.

\begin{abstract}
Pipecolic acid (Pip) is an essential component of systemic acquired resistance, priming resistance in Arabidopsis thaliana against (hemi)biotrophic pathogens. Here, we studied the potential role of Pip in bacteria-induced systemic immunity in barley. Exudates of barley leaves infected with the systemic immunity-inducing pathogen Pseudomonas syringae pv. japonica induced immune responses in A. thaliana. The same leaf exudates contained elevated Pip levels compared with those of mock-treated barley leaves. Exogenous application of Pip induced resistance in barley against the hemibiotrophic bacterial pathogen Xanthomonas translucens pv. cerealis. Furthermore, both a systemic immunity-inducing infection and exogenous application of Pip enhanced the resistance of barley against the biotrophic powdery mildew pathogen Blumeria graminis f. sp. hordei. In contrast to a systemic immunity-inducing infection, Pip application did not influence lesion formation by a systemically applied inoculum of the necrotrophic fungus Pyrenophora teres. Nitric oxide (NO) levels in barley leaves increased after Pip application. Furthermore, X. translucens pv. cerealis induced the accumulation of superoxide anion radicals and this response was stronger in Pip-pretreated compared with mock-pretreated plants. Thus, the data suggest that Pip induces barley innate immune responses by triggering NO and priming reactive oxygen species accumulation.
\end{abstract}

Keywords: Hordeum vulgare, nitric oxide, pipecolic acid, priming, plant immunity, reactive oxygen species, systemic acquired resistance

Plants are constantly challenged by various phytopathogenic organisms and have evolved complex mechanisms of defense

Current address for Timsy: Leibniz-Zentrum für Agrarlandschaftsforschung e.V., Eberswalder Str. 84, 15374 Müncheberg, Germany.

${ }^{\dagger}$ Corresponding author: A. C. Vlot: corina.vlot@helmholtz-muenchen.de

Funding: This work was funded by the Deutsche Forschungsgemeinschaft as part of TP B06 in SFB924 (to A. C. Vlot) and by the German Federal Ministry of Education and Research as part of the German Plant Phenotyping Network (grant number 031A053C).

*The $\boldsymbol{e}$-Xtra logo stands for "electronic extra" and indicates that eight supplementary figures are published online.

The author(s) declare no conflict of interest.

๑) 2019 The American Phytopathological Society
(Jones and Dangl 2006; Spoel and Dong 2012). The first contact between a plant and pathogen happens at the plant cell surface, which contains pattern recognition receptors that recognize evolutionarily conserved structures of different pathogen families as so-called pathogen-associated molecular patterns (PAMPs) (Jones and Dangl 2006; Spoel and Dong 2012; Zipfel 2014). The recognition of such molecules elicits PAMP-triggered immunity (PTI), a moderate form of resistance reducing the propagation of virulent pathogens (Jones and Dangl 2006; Spoel and Dong 2012; Zipfel 2014). Over the course of host-pathogen evolution, some pathogens evolved effector loci whose gene products suppressed PTI, resulting in effector-triggered susceptibility. Plants, in turn, evolved resistance $(R)$ genes encoding nucleotide-binding leucinerich repeat proteins that recognize effectors and elicit effectortriggered immunity (ETI), which is stronger and more durable than PTI (Cui et al. 2015; Jones and Dangl 2006; Spoel and Dong 2012).

Many different molecular processes are involved in PTI and ETI, including the elevated accumulation of nitric oxide (NO), reactive oxygen species (ROS), and the phytohormone salicylic acid (SA) (Scheler et al. 2013; Vlot et al. 2009, 2017; Wendehenne et al. 2014). SA accumulates in infected and uninfected tissues and induces the expression of defense genes, including the SA marker gene pathogenesis-related 1 (PRI) (Klessig et al. 2018; Spoel and Dong 2012; Vlot et al. 2009, 2017). SA is essential for systemic acquired resistance (SAR), a broad-spectrum defense response in systemic, uninfected parts of locally infected plants (Fu and Dong 2013; Klessig et al. 2018; Vlot et al. 2017). Whereas SA accumulation in the systemic tissue is necessary for SAR, a second parallel signaling pathway is believed to contribute to local SAR signal generation as well as to systemic signal propagation (Gao et al. 2015; Shah et al. 2014; Vernooij et al. 1994; Vlot et al. 2017; Wendehenne et al. 2014). In this pathway, increased levels of the nonprotein amino acid pipecolic acid (Pip) induce accumulation of NO and ROS, which fortify each other in a positive feedback loop (Wang et al. 2014, 2018). Subsequently, the elevated ROS levels have been proposed to increase chemical hydrolysis of $\mathrm{C}_{18}$ unsaturated fatty acids to yield the $\mathrm{C}_{9}$ dicarboxylic acid azelaic acid (AzA) (Jung et al. 2009; Wang et al. 2014; Wittek et al. 2014; Zoeller et al. 2012). AzA accumulation, in turn, stimulates glycerol-3-phosphate (G3P) biosynthesis, promoting a positive feedback loop of G3P with the predicted lipid transfer proteins DEFECTIVE IN INDUCED RESISTANCE 1 (DIR1) and AZELAIC ACID INDUCED 1 (AZI1), ultimately leading to systemic resistance (Yu et al. 2013). 
In Arabidopsis thaliana, Pip levels rise in leaves and their petiole exudates after infection of the leaves with avirulent Pseudomonas syringae (Bernsdorff et al. 2016; Návarová et al. 2012; Wang et al. 2018). In addition, genes in the Pip biosynthetic pathway, AGD2-like defense response protein 1 $(A L D 1)$ and SAR-deficient 4 (SARD4), are required for functional SAR (Ding et al. 2016; Hartmann et al. 2017; Návarová et al. 2012; Song et al. 2004). Notably, root application of Pip complements the defect of aldl in induced resistance (Návarová et al. 2012), illustrating the importance of Pip for SAR. This is likely due to Pip priming defense against pathogens, inducing a state of heightened alert that allows quicker and stronger defense responses against following pathogen attack (Bernsdorff et al. 2016; Conrath et al. 2015; Mauch-Mani et al. 2017; Návarová et al. 2012). FLAVIN-DEPENDENT MONOXYGENASE 1 (FMO1) catalyzes the conversion of Pip to its presumed bioactive derivative $\mathrm{N}$-hydroxy pipecolic acid (NHP) (Chen et al. 2018; Hartmann et al. 2018). Analogous to Pip, NHP accumulates in infected $A$. thaliana plants and this accumulation is crucial for SAR (Chen et al. 2018; Hartmann et al. 2018; Mishina and Zeier 2006). Although Pip and NHP appear to be systemically mobile (Chen et al. 2018; Návarová et al. 2012; Wang et al. 2018), experiments using petiole exudates showed that ALD1 and, thus, de novo biosynthesis of Pip is necessary in the systemic tissue for SAR signal recognition or propagation (Wang et al. 2018).

Whereas SAR is relatively well-researched in A. thaliana, much less is known about comparable mechanisms in crop plants, including monocotyledonous cereals, which are the staple foods of the human population. SAR or SAR-like responses have been observed in the monocots banana (Musa acuminata [Wu et al. 2013]), maize (Zea mays [Balmer et al. 2013]), rice (Oryza sativa [Sharma et al. 2013]), wheat (Triticum aestivum [Yang et al. 2013]), and barley (Hordeum vulgare [Dey et al. 2014]), but knowledge about the signaling molecules involved is scarce. SAR or SAR-like resistance in banana, maize, and rice has been associated with SA or SA signaling (Balmer et al. 2013; Sharma et al. 2013; Wu et al. 2013). Furthermore, SAR in wheat against Puccinia striiformis f. sp. tritici might be associated with G3P (Yang et al. 2013), but local resistance against the same pathogen was negatively associated with TaDIR1-2, an ortholog of AtDIR1, which promotes SAR in A. thaliana (Ahmed et al. 2017; Maldonado et al. 2002). We previously reported that a local infection of barley with $P$. syringae pv. japonica induces SARlike systemic immunity against the hemibiotrophic bacterium Xanthomonas translucens pv. cerealis (Dey et al. 2014). Although SA has been implicated in barley defense responses, $P$. syringae pv. japonica-induced systemic immunity was not accompanied by elevated SA accumulation in leaves or dependent on the SA signaling regulator HvNPRl (Dey et al. 2014).

SA-associated immune responses in barley (Hordeum vulgare) often are studied in interaction with Blumeria graminis f. sp. hordei, commonly named powdery mildew, an obligate biotrophic fungal pathogen that thrives on living host cells (Thordal-Christensen et al. 2000). In contrast to biotrophic pathogens of rice, B. graminis f. sp. hordei inoculation does not induce SA accumulation in infected barley leaves (Hückelhoven et al. 1999; Jain et al. 2004). Nevertheless, soil-drench treatment of barley seedlings with SA or its functional analogs 2,6-dichloroisonicotinic acid or $S$-methyl 1,2,3benzothiadiazole-7-carbothioate enhanced barley resistance to B. graminis f. sp. hordei (Beßer et al. 2000; Kogel et al. 1994, 1995). Additionally, infiltration of leaves of 3-week-old barley plants with $\mathrm{SA}$ reduced the propagation of $B$. graminis $\mathrm{f}$. $\mathrm{sp}$. hordei on the systemic leaves (Lenk et al. 2018). Similarly, local application of folic acid or AzA, which in A. thaliana induce SA-dependent resistance to hemibiotrophic bacteria, each reduced the propagation of a systemically applied $B$. graminis f. sp. hordei inoculum in barley (Jung et al. 2009; Lenk et al. 2018; Wittek et al. 2015). Thus, whereas $P$. syringae pv. japonica-induced systemic resistance against $X$. translucens pv. cerealis likely is not associated with SA (Dey et al. 2014), SA and SA-related signaling components appear relevant for barley defense against $B$. graminis f. sp. hordei.

SAR in A. thaliana depends on SA and is, in parallel, regulated by a signaling pathway that connects the SAR-associated metabolites Pip, NO-ROS, AzA, and G3P (Gao et al. 2015; Shah et al. 2014; Wang et al. 2018). Components of the Pip biosynthetic pathway have been recognized in many plant species, among them the important monocotyledonous crops wheat and barley (Garcia-Seco et al. 2017; Hartmann and Zeier 2018; Møller 1974). Pip accumulation has been observed in maize (Kiyota et al. 2015). In rice, elevated Pip levels have been associated with disease (Pálfi and Dézsi 1968). Here, we investigated the potential role of Pip in barley disease resistance and systemic immunity. The data suggest that Pip accumulates in barley after infection and contributes to immunity against (hemi)biotrophic pathogens by inducing NO and priming ROS accumulation.

\section{RESULTS}

\section{A. thaliana response to leaf exudates from infected barley leaves.}

The hemibiotrophic bacterium $P$. syringae pv. japonica induces systemic immunity in barley against the hemibiotrophic bacterium $X$. translucens pv. cerealis (Dey et al. 2014). This form of systemic immunity phenotypically resembles A. thaliana SAR. In order to test if this is, indeed, a similar process, an interspecies leaf exudate experiment was conducted. Leaf exudates from $P$. syringae pv. japonica-infiltrated and mock-treated barley cultivar Barke leaves were collected and were infiltrated into leaves of wild type $A$. thaliana plants of the cultivar Col-0. One day later, the infiltrated leaves were either harvested and analyzed for transcript accumulation of the SAR marker gene $P R I$ or inoculated with $P$. syringae pv. tomato. Leaf exudates from $P$. syringae pv. japonica-treated barley leaves significantly enhanced $P R I$ transcript accumulation in A. thaliana as compared with leaf exudates from mock-treated barley leaves (Fig. 1A). The experiment was repeated, with similar results, using leaf exudates from barley cultivar Golden Promise (Supplementary Fig. S1). Since barley leaf exudates induced a marker gene of SAR in A. thaliana, both plant species might share one or more SAR signals. In support of this hypothesis, $P$. syringae pv. tomato titers at 4 days postinoculation (dpi) were restricted in A. thaliana leaves that had been pretreated with leaf exudates from infected barley leaves as compared with those pretreated with leaf exudates from mock-treated barley leaves (Fig. 1B). The observed reduction in $P$. syringae pv. tomato growth was comparable to that induced by SAR in A. thaliana (Breitenbach et al. 2014; Riedlmeier et al. 2017). Thus, the data support the hypothesis that $A$. thaliana and barley share similar components as part of their SAR mechanisms.

\section{Pip accumulates in barley after infection and induces resistance to $X$. translucens pv. cerealis.}

We next asked which SAR component or components might be shared by A. thaliana and barley. In addition to SA, which is not induced in leaves after infection of barley with $P$. syringae pv. japonica (Dey et al. 2014), Pip is an important component of A. thaliana SAR (Bernsdorff et al. 2016; Návarová et al. 2012). Therefore, we compared its accumulation in leaf exudates collected from infected and mock-treated barley. Indeed, 
leaf exudates from $P$. syringae pv. japonica-inoculated barley contained elevated levels of Pip compared with leaf exudates from mock-treated barley leaves (Fig. 1C). In addition, Pip accumulation was monitored in infected and mock-treated barley leaves. To this end, plants were infiltrated with either P. syringae pv. japonica or a mock control solution. Four days later, the treated leaves were harvested and their Pip levels were monitored. Pip accumulated to higher levels in P. syringae pv. japonica-infected compared with mock-treated leaves (Fig. 1D). Taken together, an infection with $P$. syringae pv. japonica induced Pip accumulation in barley leaves and leaf exudates, suggesting a possible role of Pip in resistance induction by P. syringae pv. japonica.

We next tested whether Pip induces resistance in barley if exogenously applied. To this end, $30 \mu$ mole Pip per plant was applied to 3-week-old barley by irrigation and the leaves were infected with $X$. translucens pv. cerealis 3 days later. The resulting in planta $X$. translucens pv. cerealis titers at 4 dpi were significantly lower in plants pretreated with Pip compared with those in control-treated plants (Fig. 2). This suggests that exogenous Pip, in contrast to SA (Dey et al. 2014), enhanced the resistance of barley against $X$. translucens pv. cerealis.

\section{$P$. syringae pv. japonica and Pip induce resistance in barley against $B$. graminis f. sp. hordei.}

Barley is an important crop plant and yield losses due to phytopathogens are a realistic problem. Here, we tested if $P$. syringae pv. japonica or Pip can induce resistance in barley against the agronomically relevant barley-specific powdery mildew pathogen B. graminis f. sp. hordei. First, 3-week-old barley plants were inoculated with $P$. syringae pv. japonica in the first true leaf or were treated with a mock solution. Five days later, (systemic) leaf 2 of the treated plants was inoculated with B. graminis f. sp. hordei. Another 6 days later, the infected leaves were stained with DAF-FM DA (4-amino-5-methylamino-2',7'difluorofluorescein diacetate), to visualize $B$. graminis $\mathrm{f}$. sp. horde $i$ and allow quantification by fluorescence microscopy (Fig. 3A, B, D, and E, green fluorescence) (Lenk et al. 2018). For relative quantification between treatments, DAF-FM DA fluorescence associated with $B$. graminis $\mathrm{f}$. sp. horde $i$ was normalized
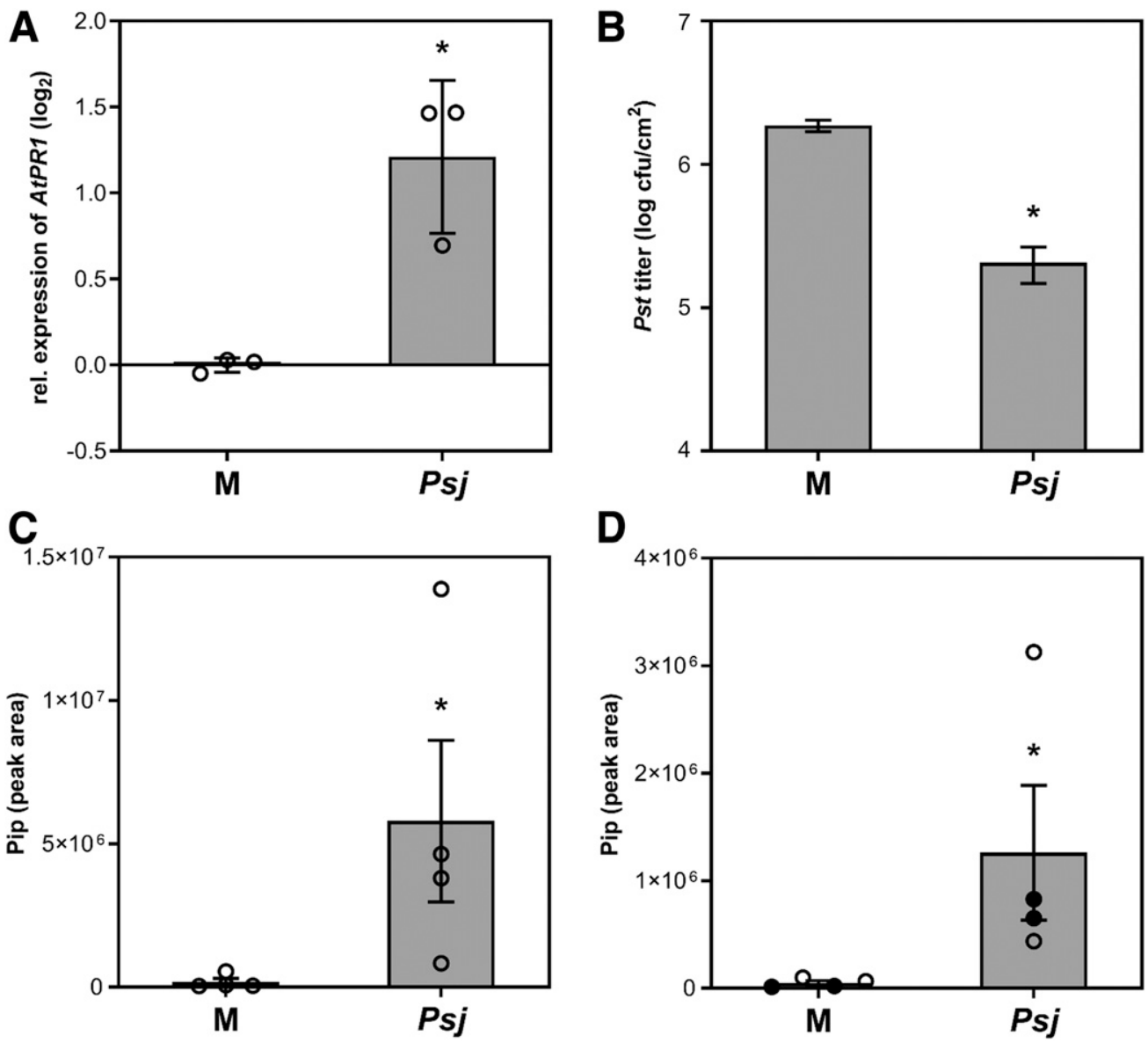

Fig. 1. Leaf exudates from infected barley leaves induce immune responses in Arabidopsis thaliana and contain elevated pipecolic acid (Pip) levels. Barley leaves were syringe-infiltrated with Pseudomonas syringae pv. japonica (Psj) or $10 \mathrm{mM} \mathrm{MgCl} 2(\mathrm{M}=$ mock) as a control. Two days later, leaf exudates were collected and infiltrated into the leaves of A. thaliana Col-0 plants or were analyzed for their Pip content. A, One day after leaf exudate infiltration, PRI transcript accumulation in A. thaliana leaves was determined relative to that of UBIQUITIN10 by reverse transcription quantitative (RT-q)PCR. Dots represent datapoints from biologically independent replicate experiments; bars represent the average of the three datapoints per treatment \pm standard deviation. B, One day after leaf exudate infiltration, the treated leaves were inoculated with $P$. syringae pv. tomato $(P s t)$. The resulting in planta $P$. syringae pv. tomato titers were determined at 4 days postinoculation. Bars represent the average of three replicates \pm standard deviation. This experiment was repeated three times with comparable results. C, The Pip content of barley leaf exudates was determined by ultra-performance liquid chromatography-mass spectrometry (UPLC-MS) analysis. Dots represent datapoints from biologically independent replicate experiments; bars indicate the average of the four datapoints per treatment \pm standard error. D, Pip content of barley leaves 4 days after their syringe-infiltration with P. syringae pv. japonica or a mock control solution as indicated below the panel. The Pip content of the treated leaves was determined by UPLC-MS. Dots represent datapoints from biologically independent replicate experiments; bars represent the average of the four datapoints per treatment \pm standard error (A, B, and D). Open circles indicate barley cultivar Barke; closed circles indicate barley cultivar Golden Promise. Asterisks above bars indicate statistically significant differences from the controls (A: paired $t$ test, $P=0.0350$; B: $t$ test, $P<$ 0.0001; C: paired $t$ test (on log-transformed data), $P=0.0190$; D: ratio paired $t$ test, $P=0.0111$ ). 
to that of untreated barley leaves. Chlorophyll (auto)fluorescence was recorded (Fig. 3A, B, D, and E, red) as a visual control to make sure all leaf discs were fully in focus when recording DAFFM DA fluorescence. As found by Lenk et al. (2018), visual differences in B. graminis f. sp. hordei infection levels that were observed between the different treatments (Supplementary Fig. $\mathrm{S} 2 \mathrm{~A}$ ) were reflected in the resulting relative DAF-FM DA fluorescence intensities (Fig. 3A to C). B. graminis f. sp. hordeiassociated DAF-FM DA fluorescence was strongly reduced if the plants had been pretreated with $P$. syringae pv. japonica, with fluorescence of treated plants being approximately $25 \%$ that of control-treated plants (Fig. 3A to C). This reduction in fluorescence indicates a reduction of fungal mass and suggests the induction of systemic resistance to $B$. graminis $\mathrm{f}$. $\mathrm{sp}$. hordei by P. syringae pv. japonica.

Second, we tested if Pip application induces resistance in barley to B. graminis f. sp. hordei. To this end, $30 \mu$ mole of Pip per plant was administered to barley by irrigation. Three days later, the plants were infected with B. graminis f. sp. hordei. At $6 \mathrm{dpi}$, the infected leaves were stained with DAF-FM DA to monitor fungal growth. Differences in the B. graminis f. sp. hordei-associated relative DAF-FM DA fluorescence of Pipand $\mathrm{H}_{2} \mathrm{O}$-treated plants reflected visual differences in disease symptoms caused by the fungus (Fig. 3D to F; Supplementary Fig. S2B). Pip treatment reduced B. graminis f. sp. hordeiassociated DAF-FM DA fluorescence compared with the $\mathrm{H}_{2} \mathrm{O}$ treated control to a similar extent as $P$. syringae pv. japonica (Fig. 3D to F). Taken together, the data suggest that both $P$. syringae pv. japonica and exogenous Pip enhance barley resistance to B. graminis f. sp. hordei.

\section{P. syringae pv. japonica but not Pip induces susceptibility in barley to Pyrenophora teres.}

SAR and SA induce resistance in A. thaliana against (hemi) biotrophic bacteria and, at the same time, enhance $A$. thaliana

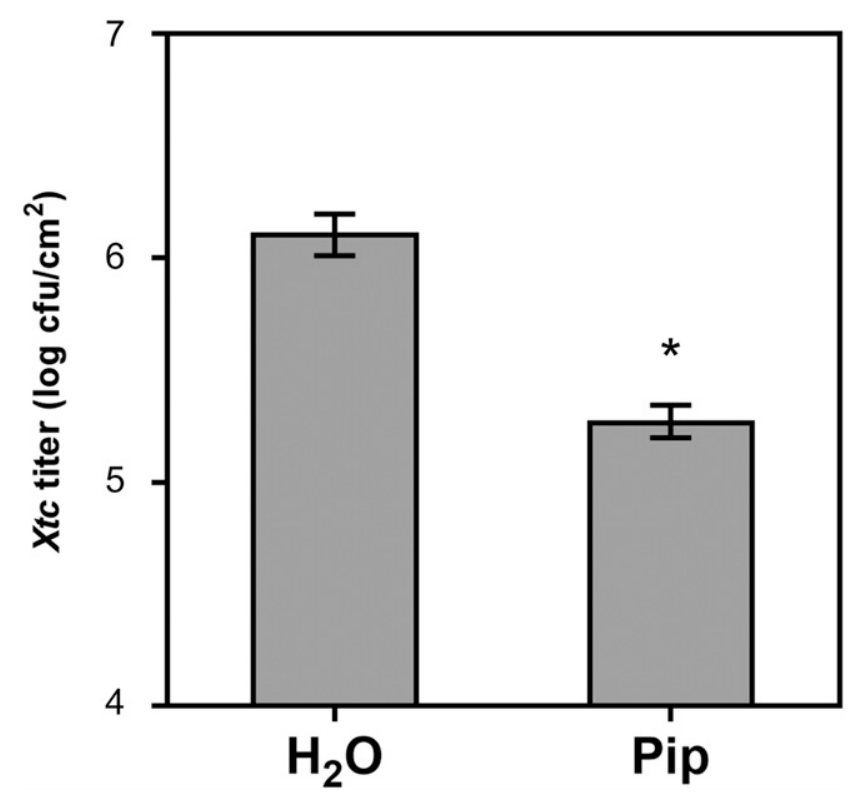

Fig. 2. Pipecolic acid (Pip) irrigation reduces Xanthomonas translucens pv. cerealis growth in barley. Barley cultivar Golden Promise plants were irrigated with Pip or $\mathrm{H}_{2} \mathrm{O}$ as the mock control treatment. Three days later, leaves of the treated plants were syringe-infiltrated with $X$. translucens $\mathrm{pv}$. cerealis $(X t c)$. The resulting in planta $X$. translucens $\mathrm{pv}$. cerealis titers were determined at 4 days postinoculation. Bars represent the average of five replicates \pm standard deviation. This experiment was repeated more than five times with comparable results. The asterisk above the bar indicates a statistically significant difference from the mock control $(t$ test, $P<$ $0.0001)$. susceptibility to the necrotrophic fungus Alternaria brassicicola (Spoel et al. 2007; Wittek et al. 2015). Here, we queried if a similar trade-off occurs in barley. To this end, we inoculated $P$. syringae pv. japonica-infected or Pip-treated barley plants with the necrotrophic fungus Pyrenophora teres. Pyrenophora teres is the causal agent of barley net blotch, a wide-spread disease that causes severe yield losses (Liu et al. 2011). In order to test for induced resistance against Pyrenophora teres, 3week-old barley plants were pretreated with either $P$. syringae pv. japonica or Pip as described above and were subsequently infected on (systemic) leaf 2 with Pyrenophora teres by placing five spore-containing droplets on the leaf surface. Inoculated leaves were photographed at $4 \mathrm{dpi}$ and the sizes of the developed necrosis and chlorosis were evaluated, using ImageJ and the macro PIDIQ (Laflamme et al. 2016; Lenk et al. 2018). Plants inoculated with $P$. syringae pv. japonica in the first true leaf developed significantly larger Pyrenophora teres lesions in their second true leaf than control plants (Fig. 4A). This suggests the induction of systemic susceptibility, albeit relatively weak, to Pyrenophora teres by $P$. syringae pv. japonica. In contrast, a pretreatment of plants with Pip did not induce a significant change in the size of lesions caused by Pyrenophora teres (Fig. 4B). Rather, there seemed to be an opposite but insignificant trend ( $t$ test, $P=0.0978$ ) for slightly smaller Pyrenophora teres lesions after Pip treatment of barley. Taken together, $P$. syringae pv. japonica induced systemic susceptibility to Pyrenophora teres, while Pip did not trigger the same adverse effect.

\section{Pip induces NO accumulation in barley.}

It was recently proposed that Pip mediates resistance in A. thaliana via the induction of NO accumulation (Wang et al. 2018). Here, we tested if Pip also induces NO accumulation in barley. To this end, we treated 3-week-old barley plants with Pip and monitored the NO content in leaves of the treated plants 3 days later by staining with the NO sensor DAF-FM DA. The fluorescence caused by DAF-FM DA was about twofold higher in plants pretreated with Pip than in control plants (Fig. 5A). Thus, Pip induces NO accumulation in barley. Because Pip primes, for example, $P R 1$ gene expression to be induced faster after a challenge inoculation of Pip-treated compared with mock-treated plants (Bernsdorff et al. 2016; Návarová et al. 2012), we tested if NO accumulation was further primed. To this end, we assessed NO accumulation using DAF-FM DA staining 1 day after inoculation of Piptreated and mock-treated plants with $X$. translucens pv. cerealis. NO accumulation was higher after $X$. translucens pv. cerealis infection of Pip-treated than of mock-treated plants (Fig. 5B). However, the observed differences in NO levels after Pip application relative to the mock treatment were stable and were not further enhanced after $X$. translucens $\mathrm{pv}$. cerealis infection (Fig. 5A and B). This suggests that Pip induced but did not further prime NO accumulation.

\section{Pip primes accumulation}

of superoxide anion radicals in barley.

In A. thaliana NO promotes SAR in a positive feedback loop with ROS, which might drive lipid peroxidation leading to the accumulation of the putative long-distance SAR signal AzA (Wang et al. 2014; Yu et al. 2013; Zoeller et al. 2012). Superoxide anion radicals $\left(\mathrm{O}_{2}^{-{ }^{-}}\right)$are highly reactive in driving lipid peroxidation in vitro (Wang et al. 2014; Zoeller et al. 2012) and have been detected in barley leaves after infection (Hückelhoven and Kogel 1998; Künstler et al. 2018; Trujillo et al. 2004). Here, we monitored $\mathrm{O}_{2}^{-}$accumulation in barley leaves after Pip irrigation of the plants and also after a subsequent infection of the treated plants with $X$. translucens pv. cerealis. $\mathrm{O}_{2}{ }^{--}$was visualized 
by nitroblue tetrazolium (NBT) staining of the leaves. In contrast to $\mathrm{NO}$ (Fig. 5A), $\mathrm{O}_{2}{ }^{--}$was not noticeably induced in leaves 3 days after irrigation of the plants with Pip, as compared with that in leaves of control-treated plants (Fig. 6A). However, $\mathrm{O}_{2}^{--}$levels were induced 1 day after inoculation of barley leaves with $X$. translucens pv. cerealis and this induction was more pronounced in Pip-treated compared with mock-treated plants (Fig. 6B). High levels of $\mathrm{O}_{2}{ }^{--}$were maintained in leaves of Pip-treated plants 2 days after infection with $X$. translucens pv. cerealis, while, in mock-treated plants, $\mathrm{O}_{2}{ }^{--}$was strongly reduced at 2 dpi compared with that at 1 dpi (Fig. 6C). Thus, the data suggest that Pip enhances the resistance of barley against $X$. translucens pv. cerealis at least in part by priming the plants for elevated and longer-lasting $\mathrm{O}_{2}^{\cdot-}$ accumulation after infection.

\section{DISCUSSION}

As components of primed and, thus, resource-efficient resistance, SAR signaling components are of interest for the protection of (crop) plants from disease as an alternative to,

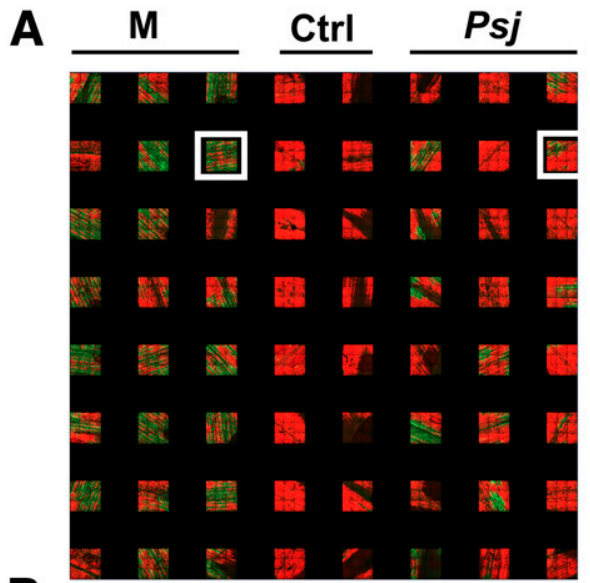

B

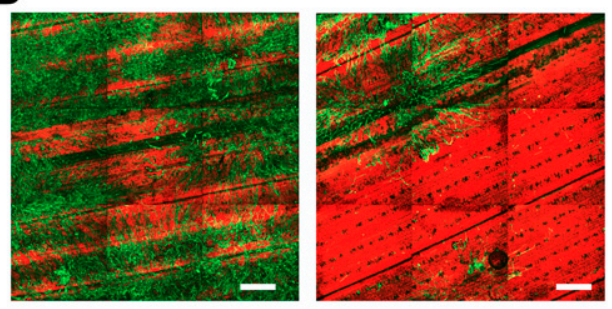

C

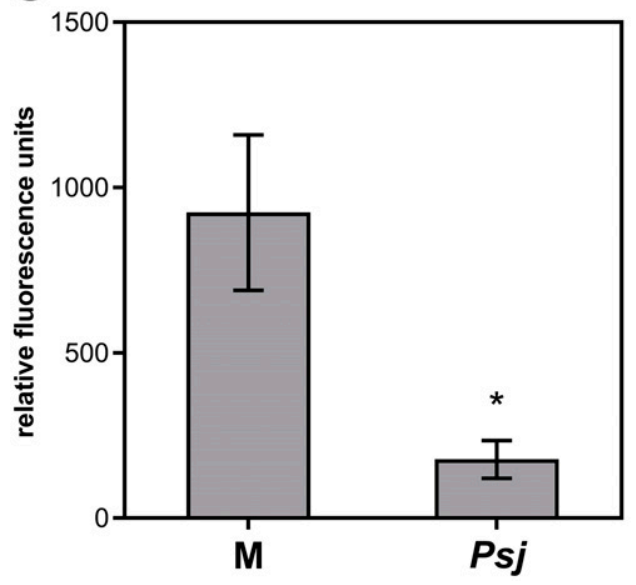

D

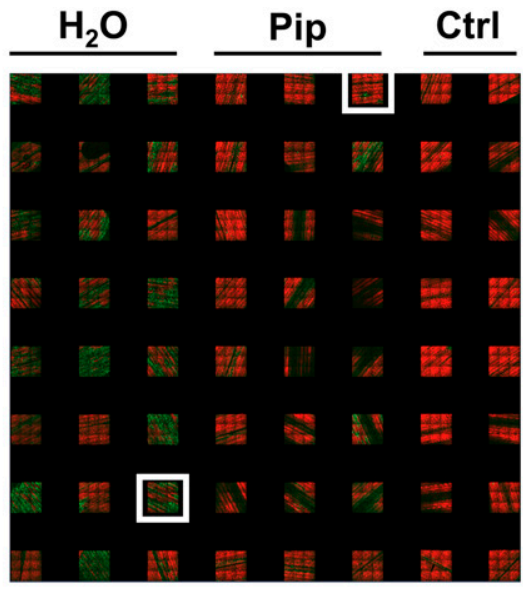

E
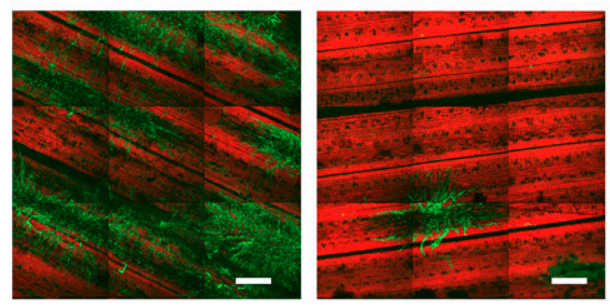

$\mathbf{F}$

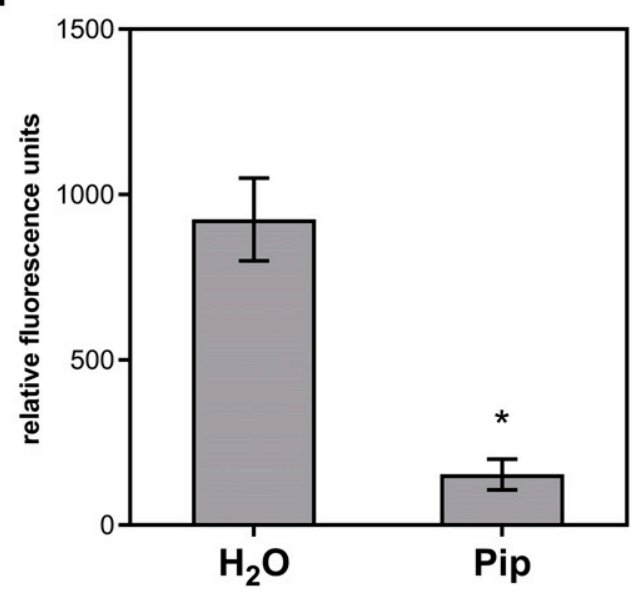

Fig. 3. Pseudomonas syringae pv. japonica and pipecolic acid (Pip) reduce propagation of a systemically applied Blumeria graminis f. sp. hordei inoculum in barley. A to $\mathbf{C}$, Leaves of barley cultivar Golden Promise plants were syringe-infiltrated with $P$. syringae pv. japonica $(P s j)$ or $10 \mathrm{mM} \mathrm{MgCl}_{2}$ as the mock $(\mathbf{M})$ control treatment. Five days later, systemic leaves of the treated plants were inoculated with B. graminis f. sp. hordei. D to F, Barley cultivar Golden Promise plants were irrigated with Pip or $\mathrm{H}_{2} \mathrm{O}$ as the mock control treatment. Three days later, leaves of the treated plants were inoculated with $B$. graminis f. sp. hordei. In planta propagation of $B$. graminis $\mathrm{f}$. sp. horde $i$ was evaluated at 6 days postinoculation. To this end, leaf discs were harvested, were stained with DAF-FM DA (4-amino-5-methylamino-2',7'-difluorofluorescein diacetate), and were mounted on 96-well plates. Fluorescence was recorded with a spinning disc (confocal) microscope. A and D display merged $z$-stack $3 \times 3$ tiled images of leaf discs in the first eight columns of a 96-well plate. DAF-FM DA fluorescence is shown in green, chlorophyll fluorescence in red. Plant treatments are indicated above the panels. Ctrl = untreated and uninfected controls used for background correction of the data. The images that are highlighted with white borders in A and D are enlarged in B and E, respectively (Scale bar $=500 \mu \mathrm{m})$. C and F show DAF-FM DA fluorescence in leaf discs of $B$. graminis f. sp. hordei-infected plants quantified relative to that of untreated and uninfected control plants. Bars represent the average of 20 (mock) and 17 (P. syringae pv. japonica) $(\mathrm{C})$ or $22\left(\mathrm{H}_{2} \mathrm{O}\right)$ and 23 (Pip) (F) replicates \pm standard error. Asterisks above bars indicate statistically significant differences from the mock controls (C: $t$ test with Welch's correction, $P=0.0055$; F: $t$ test with Welch's correction, $P<0.0001)$. These experiments were repeated four $(\mathrm{F})$ to five $(\mathrm{C})$ times with comparable results. 
e.g., fungicides or pesticides. Using bacteria to induce resistance might prove to be problematic in agriculture, and the induction of a primed state via chemicals is more feasible. Until now, not much is known about the transferability of knowledge on SAR from the model plant A. thaliana to crop plants, including barley. We found that leaf exudates of barley infiltrated with $P$. syringae pv. japonica increased $P R I$ expression when infiltrated into leaves of $A$. thaliana and that this was associated with enhanced resistance of the treated $A$. thaliana leaves against $P$. syringae pv. tomato (Fig. 1). This data suggests that barley and $A$. thaliana share common signals in defense induction. It is possible that these signals are associated with SA signaling, the hallmark phytohormone associated with SAR in A. thaliana (Klessig et al. 2018; Vlot et al. 2009, 2017). We and others have shown that SA induces the resistance of barley against B. graminis f. sp. hordei, and we show here that $P$. syringae pv. japonica-induced systemic resistance also acts against B. graminis f. sp. hordei (Fig. 3) (Beßer et al. 2000; Kogel et al. 1995; Lenk et al. 2018). However, in contrast to $P$. syringae pv. japonica, SA does not enhance the resistance of barley against $X$. translucens pv. cerealis, while the SA or SAR signaling-inducing compounds folic acid and AzA appear to raise the susceptibility of barley to X. translucens pv. cerealis (Dey et al. 2014; Lenk et al. 2018). Therefore, signaling components other than SA likely are involved in $P$. syringae pv. japonica-triggered systemic immunity in barley. Here, we show that these signaling components might include Pip.
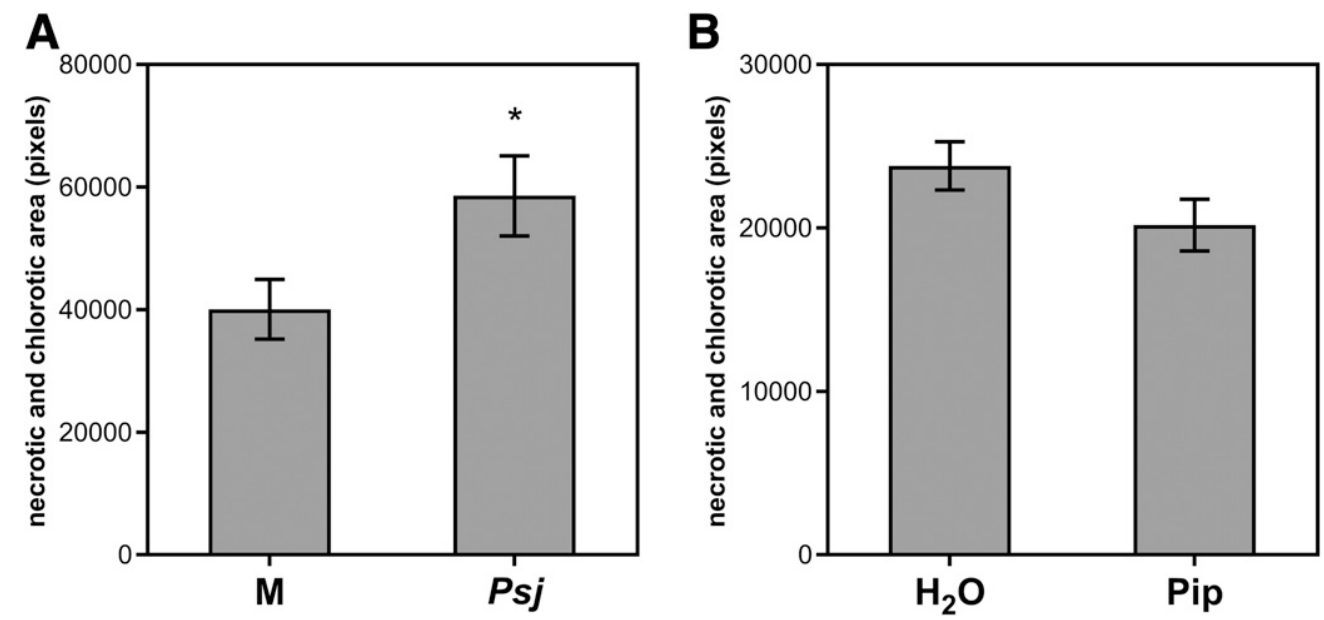

Fig. 4. Pseudomonas syringae pv. japonica but not pipecolic acid (Pip) enhances the size of Pyrenophora teres lesions on barley. A, Leaves of barley cultivar Golden Promise plants were syringe-infiltrated with $P$. syringae pv. japonica ( $P$ sj) or $10 \mathrm{mM} \mathrm{MgCl}_{2}$ as the mock (M) control as indicated below the bars. Five days later, systemic leaves were inoculated with Pyrenophora teres. B, Barley cultivar Golden Promise plants were irrigated with Pip or $\mathrm{H}_{2} \mathrm{O}$ as the mock control treatment. Three days later, Pyrenophora teres spores were applied to leaves of the treated plants. Leaves were photographed at 4 days postinoculation, and the necrotic and chlorotic areas were quantified using the ImageJ macro PIDIQ. Bars represent the average of 36 (mock and $P$. syringae pv. japonica) (A) or $43\left(\mathrm{H}_{2} \mathrm{O}\right)$ and 45 (Pip) (B) replicates from six (A) to nine (B) biologically independent experiments \pm standard error. The asterisk above the bar indicates a statistically significant difference from the mock control (A: $t$ test, $P=0.0109$; B: $t$ test, $P=0.0978$ ).
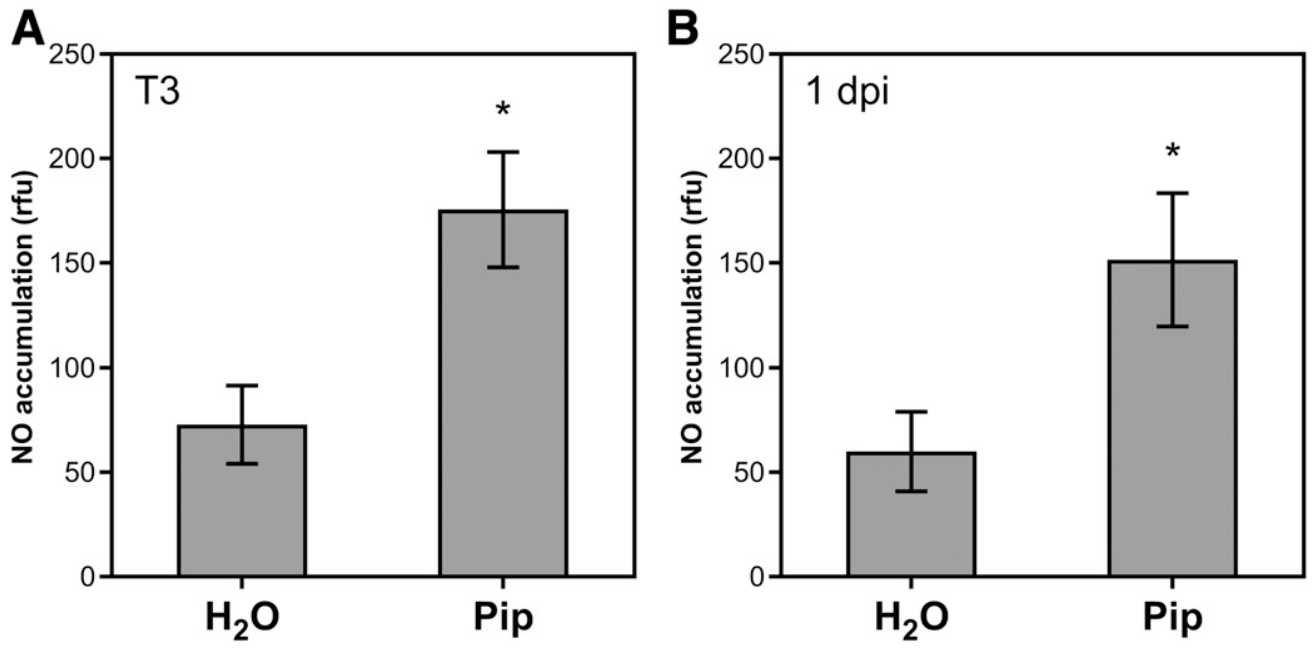

Fig. 5. Pipecolic acid (Pip) application induces nitric oxide (NO) accumulation in barley. A and B, Barley cultivar Golden Promise plants were irrigated with Pip or $\mathrm{H}_{2} \mathrm{O}$ as the mock control treatment. Three days later (T3), leaves were harvested (A) or syringe-infiltrated with Xanthomonas translucens pv. cerealis (B). X. translucens pv. cerealis-inoculated leaves were harvested at 1 day postinoculation. NO levels were monitored by DAF-FM DA (4-amino-5-methylamino-2',7'-difluorofluorescein diacetate) staining of leaf discs. The resulting DAF-FM DA fluorescence in treated plants was quantified relative to that in untreated plants. Bars represent the average of 16 leaf discs from four plants \pm standard error. Asterisks above bars indicate statistically significant differences from the mock controls (A: $t$ test, $P=0.0044$; B: $t$ test, $P=0.0198$ ). These experiments were repeated two (B: both in the greenhouse) to six (A: two in growth chamber, four in greenhouse) times with comparable results. rfu = relative fluorescence units. 
Pip levels rose in barley leaves and leaf exudates after infection of the leaves with P. syringae pv. japonica (Fig. 1). The Pip levels we observed in barley leaf exudates ranged between about 0.5 and about $17 \mathrm{ng}$ per milliliter and were thus on average about five- to 10 -fold lower than those reported in A. thaliana (Supplementary Fig. S3) (Návarová et al. 2012). Because low levels of Pip neither induced PRI expression nor resistance to $P$. syringae pv. tomato upon infiltration into A. thaliana leaves (Wang et al. 2018), barley leaf exudates probably contained at least one additional component that induced these responses, either alone or in cooperation with Pip. One possible candidate molecule is SA. In contrast to SA in leaves (Dey et al. 2014), SA levels were induced in leaf exudates of barley after $P$. syringae pv. japonica inoculation of the leaves (Supplementary Fig. S4). Although SA levels remained relatively low at about $1.5 \mathrm{ng}$ per milliliter, perhaps this sufficed to induce $P R 1$ expression and resistance against $P$. syringae $\mathrm{pv}$. tomato in A. thaliana in cooperation with Pip (Bernsdorff et al. 2016). Alternatively, other or additional molecular components in barley leaf exudates might have contributed to these responses. Notably, P. syringae pv. japonica inoculation of barley leaves did not alter the accumulation of the SAR-associated priming signal AzA in the leaves but significantly enhanced its levels in leaf exudates (Supplementary Fig. S5C and D). AzA primes $A$. thaliana to rapidly accumulate $P R l$ transcripts after $P$. syringae pv. tomato and enhances the systemic resistance of $A$. thaliana against $P$. syringae pv. tomato and that of barley against $B$. graminis f. sp. hordei (Jung et al. 2009; Lenk et al. 2018). Perhaps, Pip, SA, AzA, and additional not yet identified molecular components in barley leaf exudates cooperated, singly or in combination, to induce $P R I$ transcript accumulation and resistance in A. thaliana.

Similarly to P. syringae pv. japonica (Dey et al. 2014), Pip induced resistance in barley against the hemibiotrophic bacterium $X$. translucens pv. cerealis (Fig. 2). This Pip-induced protection of barley was comparable to that of $A$. thaliana against the hemibiotrophic bacterium $P$. syringae pv. maculicola (Návarová et al. 2012; Wang et al. 2018). Moreover, treatment of barley plants with $30 \mu$ mole of Pip by irrigation (the treatment used throughout this study), raised Pip levels in the leaves; the resulting in planta Pip levels were approximately 10-fold lower than those observed after infection of barley leaves with $P$. syringae pv. japonica (compare Supplementary Fig. S6 with Figure 1D). This argues in favor of the potential physiological relevance of resistance responses induced by exogenous Pip application and their possible reflection of in vivo responses occurring in barley after $P$. syringae pv. japonica infection. Furthermore, both $P$. syringae pv. japonica and Pip enhanced the resistance of barley against $B$. graminis f. sp. hordei (Fig. 3). Thus, both P. syringae pv. japonica- and Pip-induced resistance appeared to be functional in barley against (hemi)biotrophic pathogens, and the collective data suggest that Pip contributes to systemic immune responses triggered by a local $P$. syringae pv. japonica infection of barley.

At the same time, $P$. syringae pv. japonica enhanced the systemic susceptibility of barley to the necrotrophic fungus Pyrenophora teres (Fig. 4). Similarly, treatment of A. thaliana with $P$. syringae pv. tomato (i.e., SAR), SA, or folic acid induces susceptibility to necrotrophic Alternaria brassicicola in the treated tissues (Spoel et al. 2007; Wittek et al. 2015). This likely happens due to antagonistic crosstalk between SA and jasmonic acid (JA) signaling, with $P$. syringae pv. tomatoinduced SA inhibiting JA-mediated defense against Alternaria brassicicola (Pieterse et al. 2012; Spoel et al. 2007). Whereas this effect does not emanate to the systemic tissues of A. thaliana, barley seems to support changes in the systemic leaves of $P$. syringae pv. japonica-infected plants that enhance
Pyrenophora teres growth (Fig. 4), suggesting antagonistic effects on systemic responses of barley to biotrophic and necrotrophic pathogens. Such antagonistic crosstalk between defense responses against biotrophic and necrotrophic pathogens has previously been observed. Barley plants with a mutation in Mlo are completely resistant to the biotrophic fungus B. graminis f. sp. hordei (Büschges et al. 1997). At the same time, mlo plants display increased susceptibility to necrotrophic Fusarium graminearum (Jansen et al. 2005).

Enhanced Pyrenophora teres growth systemic to a local $P$. syringae pv. japonica infection was independent of Pip. If at all, Pip might reduce the size of Pyrenophora teres lesions rather than increasing them, but this trend was not significant across multiple biologically independent experiments (Fig. 4). These data support our hypothesis (outlined above) that additional signals other than Pip likely are released after $P$. syringae pv. japonica inoculation of barley to affect systemic defense responses. It is possible that the A. thaliana SAR signals SA and AzA are involved in $P$. syringae pv. japonica-induced susceptibility to Pyrenophora teres. Alternatively, abscisic acid (ABA) and methyl jasmonate (MeJA) have each been

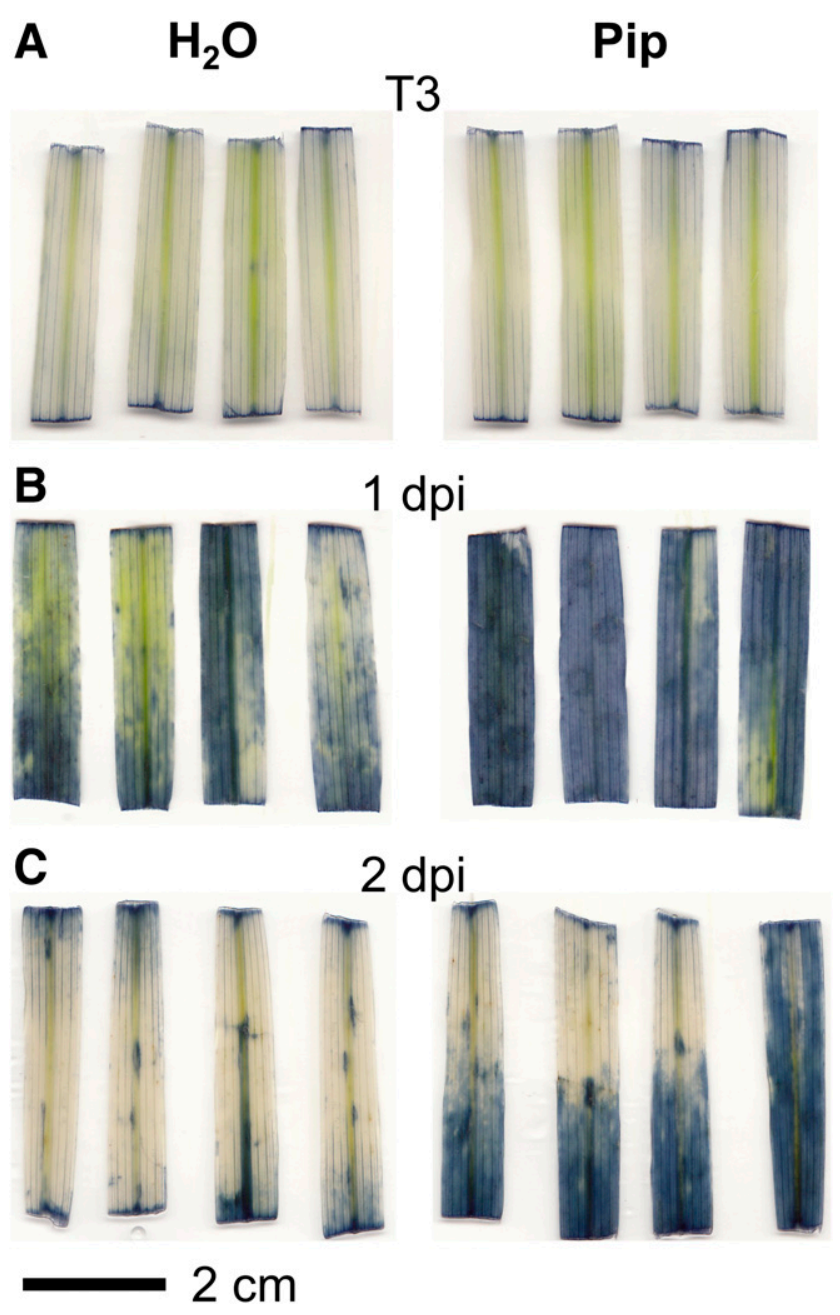

Fig. 6. Pipecolic acid (Pip) application primes superoxide anion radical accumulation. A to $\mathbf{C}$, Barley cultivar Golden Promise plants were irrigated with Pip or $\mathrm{H}_{2} \mathrm{O}$ as the mock control treatment. Three days later (T3), leaves were harvested (A) or syringe-infiltrated with Xanthomonas translucens pv. cerealis (B and C). X. translucens pv. cerealis-inoculated leaves were harvested at 1 (B) and 2 days postinoculation (C). The accumulation of superoxide anion radicals was monitored by staining leaf fragments with nitroblue tetrazolium. These experiments were repeated three times with comparable results. 
associated with $P$. syringae pv. japonica-induced systemic immunity against $X$. translucens pv. cerealis in barley (Dey et al. 2014) and might also be involved in systemic susceptibility to Pyrenophora teres. However, the application of SA, AzA, ABA, and MeJA did not induce susceptibility to Pyrenophora teres when applied at the concentrations that induced resistance against $X$. translucens pv. cerealis (Lenk et al. 2018; Supplementary Fig. S7). It is possible that either other concentrations are needed or several compounds need to work in concert during $P$. syringae pv. japonica-induced susceptibility to Pyrenophora teres. Alternatively, different compounds not yet identified might cause the increased size of Pyrenophora teres lesions.

In a manner similar to its presumed activity in A. thaliana, Pip induced NO accumulation in barley leaves when exogenously applied (Fig. 5). Furthermore, Pip plays a crucial role in priming plant immune responses during SAR (Bernsdorff et al. 2016; Návarová et al. 2012; Zeier 2013). AtPRl transcript accumulation, for example, does not appear to be robustly induced by Pip but is exaggerated in response to infection if the plants had been treated or 'primed' with Pip before the infection (Bernsdorff et al. 2016; Návarová et al. 2012). Here, we show that the accumulation of $\mathrm{O}_{2}^{--}$in response to $X$. translucens pv. cerealis inoculation likely is primed after Pip application (Fig. 6). Interestingly, $\mathrm{NO}$ has been shown to interact with $\mathrm{O}_{2}{ }^{--}$ in plants, forming peroxynitrite $\left(\mathrm{ONOO}^{-}\right)$, which is cytotoxic, but is not highly effective on plant cells and is therefore believed to play a role in plant immunity (Delledonne et al. 2001). Although the data do not allow conclusions on direct signaling connections, the findings from this work suggest interesting parallels in the molecular mechanisms through which Pip contributes to immunity in A. thaliana and barley. In both plant species, SAR-inducing infections induce Pip accumulation, while exogenous Pip application induces NO accumulation (Wang et al. 2018) (Figs. 1 and 5). In A. thaliana NO promotes SAR in a positive feedback loop with ROS acting upstream of other SAR-associated signals, including AzA and G3P (Wang et al. 2014; Zoeller et al. 2012). In support of a role of this pathway in SAR in cereal crops, G3P has been associated with systemic immune responses in wheat (Yang et al. 2013). In barley, further work is required to establish whether Pip-primed accumulation of $\mathrm{O}_{2}{ }^{--}$is regulated by $\mathrm{NO}$ and if this results in elevated G3P accumulation. Nevertheless, our cumulative data suggest that at least part of the SAR-promoting Pip, NO-ROS, AzA, G3P pathway exists in barley and might be active in systemic immunity.

In this study, we investigated the role of Pip in induced resistance of barley. Pip application reduced growth of systemically applied (hemi)biotrophic pathogens and did not appear to negatively affect defense against the necrotrophic fungus $P y r-$ enophora teres. This makes Pip an interesting candidate molecule for crop protection, since it might protect plants from biotrophic pathogens while not leaving them vulnerable to necrotrophic pathogens. Although we found good evidence for transferability of Pip-induced resistance mechanisms between the A. thaliana model and the crop plant barley, further research is required to uncover Pip-induced molecular mechanisms triggering immunity in barley.

\section{MATERIALS AND METHODS}

Plants and growth conditions.

Barley seeds (Hordeum vulgare L. cultivars Golden Promise or Barke) were sterilized in $1.2 \%$ sodium hypochlorite for $3 \mathrm{~min}$ with 25 inversions per minute. Subsequently, seeds were rinsed three times with water for 10 min with 25 inversions per minute and were then sown (Floradur Anzuchtsubstrat B Seed,
Floragard; mixed 5:1 with sand for Pip irrigation experiments and Einheitserde classic CL-T, Bayerische Gärtnereigenossenschaft for all other experiments). Plants for B. graminis f. sp. hordei infections were grown in climate chambers with $16 \mathrm{~h}$ of light and $8 \mathrm{~h}$ of darkness at a temperature of $20^{\circ} \mathrm{C}$ (day) and $16^{\circ} \mathrm{C}$ (night). Plants for all other experiments were grown in a greenhouse with additional lights HQI-TS 400W/D (Osram), using a day and night cycle of $12 \mathrm{~h}$ with $24^{\circ} \mathrm{C}$ during the day and $20^{\circ} \mathrm{C}$ during the night. NO quantification was performed in both greenhouse and chamber-grown plants. Three-week-old plants were used for all experiments.

Arabidopsis thaliana ecotype Columbia-0 (Col-0) was grown as described (Breitenbach et al. 2014). Two weeks after germination, plants were treated with Biomükk by soil-drench application, according to the manufacturer instructions (Biofa AG, Münsingen, Germany). Four- to five-week-old plants were used for experiments.

\section{Biological and chemical pretreatments.}

Pip (Sigma-Aldrich) was applied by irrigation, essentially as described (Návarová et al. 2012), at an amount of 30 mole per plant. $\mathrm{H}_{2} \mathrm{O}$ served as the mock treatment. Three days later, the treated plants were inoculated in the second true leaves with $X$. translucens pv. cerealis, B. graminis f. sp. hordei, or Pyrenophora teres as described below.

For systemic immunity analyses the first true leaves of barley plants were infiltrated with $10^{6} \mathrm{CFU}$ of $P$. syringae pv. japonica per milliliter or with $10 \mathrm{mM} \mathrm{MgCl} 2$ as the mock treatment, as described (Dey et al. 2014). Five days later, the second true leaves of the treated plants were inoculated with $X$. translucens pv. cerealis, B. graminis f. sp. hordei, or Pyrenophora teres as described below.

ABA and MeJA (Sigma-Aldrich) were dissolved at $400 \mathrm{mM}$ in $100 \%$ methanol (MeOH; Merck), were diluted to $100 \mu \mathrm{M}$ in $10 \mathrm{mM} \mathrm{MgCl}_{2}$ (Roth), and were syringe-infiltrated into the first true leaf of barley plants. As a mock treatment, $0.025 \% \mathrm{MeOH}$ in $10 \mathrm{mM} \mathrm{MgCl}_{2}$ was used. Five days later, the second true leaves of the treated plants were infected with Pyrenophora teres as described below.

\section{Infections and analysis.}

$P$. syringae pv. japonica (strain LMG5659) and X. translucens pv. cerealis (strain LMG7393) from the LMG collection of the Belgian Coordinated Collections of Microorganisms were propagated and inoculated as described (Dey et al. 2014). $X$. translucens pv. cerealis inoculations were performed by leaf infiltration a concentration of $10^{5} \mathrm{CFU} / \mathrm{ml}$ in $10 \mathrm{mM} \mathrm{MgCl}_{2}$. In planta $X$. translucens pv. cerealis titers were determined at 4 dpi, as described (Dey et al. 2014).

B. graminis f. sp. hordei Swiss field isolate $\mathrm{CH} 4.8$ from P. Schweizer (Leibniz-Institut für Pflanzengenetik und Kulturpflanzenforschung) was propagated and inoculated as described (Delventhal et al. 2017; Lenk et al. 2018). Inoculations were performed at a density of approximately 30 fungal spores per square millimeter of leaf. In planta $B$. graminis $\mathrm{f}$. $\mathrm{sp}$. hordei propagation was determined at 6 days after inoculation, essentially as described by Lenk et al. (2018), except that B. graminis f. sp. horde $i$ was stained in leaf discs taken from the proximal (and not distal) halves of the analyzed leaves.

Pyrenophora teres was propagated and inoculated as described by Lenk et al. (2018). Leaves were inoculated with 3- $\mu$ l droplets containing 65 to110 fungal spores per microliter, with each leaf receiving five droplets, alternatingly on each side of the leaf midrib. Lesions caused by Pyrenophora teres were measured at 4 days after infection using Fiji/ImageJ (version 1.52i) (Schindelin et al. 2012) and the macro PIDIQ, essentially as described (Laflamme et al. 2016; Lenk et al. 2018). The 
macro was modified to measure the necrotic and chlorotic area caused by Pyrenophora teres. These modifications were restricted to the values used for color characterization. The values used in this work were as follows: hue 0 to 45 , saturation 150 to 255 , brightness 0 to 255 .

A. thaliana leaves were syringe-infiltrated with $10^{5} \mathrm{CFU}$ of $P$. syringae pv. tomato per milliliter, and the resulting in planta $P$. syringae pv. tomato titers were determined at $4 \mathrm{dpi}$, as described by Breitenbach (et al. 2014).

\section{Leaf exudate experiment.}

The leaf exudate collection was modified from the work of Maldonado et al. (2002). Barley plants were inoculated with $P$. syringae pv. japonica as described above. Two days later, the infected leaves plus $2 \mathrm{~cm}$ of their leaf sheaths were cut off. Leaves were surface-sterilized in 50\% ethanol and were washed with $1 \mathrm{mM}$ EDTA, pH 8.5. The cut sites of the leaves were submerged in $1 \mathrm{mM}$ EDTA, $\mathrm{pH} 8.5$, which contained $100 \mu \mathrm{g}$ of ampicillin per milliliter and was exchanged for sterile $\mathrm{H}_{2} \mathrm{O}$ after $1 \mathrm{~h}$. The leaves were kept at high humidity in the dark for 2 days. The resulting exudates were filter-sterilized $(0.22 \mu \mathrm{M}$ filters; Merck Millipore) and were supplemented with $\mathrm{MgCl}_{2}$ to a final concentration of $1 \mu \mathrm{M}$. This solution was syringe-infiltrated into the third and fourth true leaves of 4- to 5-week-old A. thaliana plants. One day later, the infiltrated leaves were either harvested for RNA extraction as described below or were inoculated with $P$. syringae pv. tomato as described above. Remains of exudates were freeze-dried, were dissolved in acetonitrile $/ \mathrm{H}_{2} \mathrm{O}$ (50:50), and were used for liquid chromatography-mass spectrometry (LC-MS) measurements as described below.

\section{RNA isolation and RT-qPCR.}

RNA was isolated using TRI reagent (Sigma-Aldrich) according to manufacturer instructions. cDNA was synthesized from $1.5 \mu \mathrm{g}$ of RNA using SuperScriptII (Invitrogen, Thermo Fisher). RT-qPCR was performed with the SensiMix SYBR low ROX kit (Bioline, Meridian Bioscience) on a 7500 Fast qPCR system (Applied Biosystems, Thermo Fisher). Cycle threshold values were obtained using Sequence Detection Software (version 1.3.1, Applied Biosystems, Thermo Fisher). Primers used for qPCR were taken from the work of Breitenbach et al. (2014).

\section{Extraction of metabolites from barley leaves.}

For extraction of metabolites after infection, the first and third true leaves of barley plants were syringe-infiltrated with $10^{6} \mathrm{CFU}$ of $P$. syringae pv. japonica per milliliter, as described (Dey et al. 2014), or with $10 \mathrm{mM} \mathrm{MgCl}{ }_{2}$ as the mock treatment. Four days later, the infiltrated leaves of 10 plants per treatment were harvested. For extraction of metabolites after Pip irrigation, barley plants were treated with Pip as described above or with $\mathrm{H}_{2} \mathrm{O}$ as the mock treatment. Three days later, the second leaves of the plants were harvested.

Leaves were pooled and were ground in liquid nitrogen. Samples ( $3 \mathrm{~g}$ each) were extracted as described by Wittek et al. (2014). Briefly, $30 \mathrm{ml}$ of $100 \% \mathrm{MeOH}$ were added and were mixed for $1 \mathrm{~h}$, while rotating at $28 \mathrm{rpm}$. After centrifugation at 2,800 $\mathrm{rpm}$ and $4^{\circ} \mathrm{C}$ for $10 \mathrm{~min}$, the supernatant was dried by evaporation and was dissolved in $1 \mathrm{ml}$ of $100 \% \mathrm{MeOH}$; $9 \mathrm{ml}$ of $\mathrm{H}_{2} \mathrm{O}$ and $10 \mathrm{ml}$ of petroleum ether (PE) were added. The PE phase was transferred into a new flask, was dried by evaporation, was dissolved in acetonitrile/ $\mathrm{H}_{2} \mathrm{O}$ (50:50), and was used for LC-MS measurements as described below.

\section{ultra-performance liquid chromatography} mass spectrometry (UPLC-MS) measurements.

Samples were analyzed by UPLC ultra-high resolution tandem quadrupole/time-of-flight MS performed on a Ultimate
3000RS (Thermo Fisher) coupled to Impact II with Apollo II ESI source (Bruker). The chromatographic separation was achieved on a $\mathrm{BEH} \mathrm{C}_{18}$ reverse-phase column $(150 \times 2.1 \mathrm{~mm}$, $1.7 \mu \mathrm{m}$ particles; Waters Technologies). Eluent A was water with $0.2 \%$ of formic acid and eluent B was acetonitrile $100 \%$. The gradient elution started with an initial isocratic hold of $5 \%$ B for $5 \mathrm{~min}$, followed by an increase to $20 \%$ B until $7 \mathrm{~min}$, $50 \%$ B until 8 min, $95 \%$ B until 9 min, decreasing to $70 \% \mathrm{~B}$ until $11 \mathrm{~min}$, and 50\% B until $12 \mathrm{~min}$. Finally, the initial conditions of $5 \% \mathrm{~B}$ were reached after $14 \mathrm{~min}$. The flowrate was $200 \mu \mathrm{l} \mathrm{min}{ }^{-1}$ and the column temperature was maintained at $30^{\circ} \mathrm{C}$. The auto-sampler temperature was set at $8^{\circ} \mathrm{C}$. Mass calibration was achieved with $50 \mathrm{ml}$ of water, $50 \mathrm{ml}$ of isopropanol, $1 \mathrm{ml}$ of sodium hydroxide, and $200 \mu \mathrm{l}$ of formic acid. To measure Pip, $10 \mu$ per sample was injected and two technical replicates were measured in positive ionization mode. To measure AzA and SA, $10 \mu \mathrm{l}$ per sample was injected and two technical replicates were measured in negative ionization mode. The MS was operated as follows. The nebulizer pressure was set to 2 bar, dry gas flow was 10 liters per minute, dry gas temperature was $220^{\circ} \mathrm{C}$, capillary voltage was set at $4,000 \mathrm{~V}$ for the positive mode and at $3,000 \mathrm{~V}$ for the negative mode, the end plate offset was $500 \mathrm{~V}$. Mass spectra were acquired in a mass range of 50 to $1300 \mathrm{~m} / \mathrm{z}$. Pip, AzA, and SA were identified using authentic standards (Sigma-Aldrich) based on retention time (Pip, 2.1 to $2.4 \mathrm{~min}$; AzA, $10.9 \mathrm{~min}$; $\mathrm{SA}, 11.1$ to $11.5 \mathrm{~min}$ ) and $\mathrm{m} / \mathrm{z}$ (Pip, 130.0860; AzA, 187.0973; SA, 137.0250). For Pip and AzA, the fragmentation patterns in MS/MS mode were compared between the authentic standards and representative samples (Supplementary Figs. S5A and B and S8). Pip was quantified against external standard curves with six calibration points $(0.05$ to $500 \mathrm{pg} / \mu \mathrm{l}$, $\mathrm{R}=0.999)$. SA was quantified against an external standard curve with seven calibration points (10 to $500 \mathrm{pg} / \mu \mathrm{l}, \mathrm{R}=$ 0.999).

\section{DAF-FM DA and NBT staining.}

NO accumulation was monitored in the second true leaf of Pip- and $\mathrm{H}_{2} \mathrm{O}$-treated plants by using DAF-FM DA staining. In addition, $B$. graminis $\mathrm{f}$. sp. hordei propagation was quantified after staining the fungus with DAF-FM DA. To this end, leaf discs were treated with DAF-FM DA as described by Lenk et al. (2018) and were distributed onto the wells of 96-well plates, which had been filled with $1 \%$ phytoagar. DAF-FM DA fluorescence was subsequently excited with a $488 \mathrm{~nm}$ laser and was detected using a 525/50 bandpass filter (Axio Observer.Z1; Zeiss). Chlorophyll fluorescence was excited with a 561-nm laser and was detected using a 629/62 bandpass filter. Fluorescence intensities were analyzed using ZEN2 (Zeiss) and were normalized to DAF-FM DA background fluorescence in untreated barley plants.

NBT staining of leaf fragments $(4 \mathrm{~cm}$ long, taken from the basal leaf half) was performed exactly as described (Riedlmeier et al. 2017). Stained leaf fragments were recorded using a scanner (Canon LiDE 210). Background was subtracted with a rolling ball radius of 500 pixels using ImageJ.

\section{Statistics.}

Data were analyzed in GraphPad Prism 8 for Windows (version 8.1.1). In order to test for Gaussian distribution, experiments with four to seven replicates per sample were analyzed using the Shapiro-Wilk normality test and experiments with more replicates were analyzed using the D'AgostinoPearson normality test, both with $\alpha=0.01$. If necessary, data were $\log _{2}$ transformed to reach normal distribution. Outliers were removed in experiments with $n>3$, using Grubbs' test with $\alpha=0.05$. Data were analyzed using paired (as indicated in 
figured captions) or unpaired $t$ tests. In case of unequal variances, a $t$ test with Welch's correction was performed.

\section{ACKNOWLEDGMENTS}

We thank R. Hückelhoven and S. Engelhardt for helpful discussion and the P. Schweizer lab (IPK Gatersleben) for B. graminis f. sp. hordei and advice on inoculation methods.

\section{LITERATURE CITED}

Ahmed, S. M., Liu, P., Xue, Q., Ji, C., Qi, T., Guo, J., Guo, J., and Kang, Z. 2017. TaDIR1-2, a wheat ortholog of lipid transfer protein AtDIR1 contributes to negative regulation of wheat resistance against Puccinia striiformis f. sp. tritici. Front. Plant Sci. 8:521.

Balmer, D., de Papajewski, D. V., Planchamp, C., Glauser, G., and MauchMani, B. 2013. Induced resistance in maize is based on organ-specific defence responses. Plant J. 74:213-225.

Bernsdorff, F., Döring, A. C., Gruner, K., Schuck, S., Bräutigam, A., and Zeier, J. 2016. Pipecolic acid orchestrates plant systemic acquired resistance and defense priming via salicylic acid-dependent and -independent pathways. Plant Cell 28:102-129.

Beßer, K., Jarosch, B., Langen, G., and Kogel, K.-H. 2000. Expression analysis of genes induced in barley after chemical activation reveals distinct disease resistance pathways. Mol. Plant Pathol. 1:277-286.

Breitenbach, H. H., Wenig, M., Wittek, F., Jordá, L., Maldonado-Alconada, A. M., Sarioglu, H., Colby, T., Knappe, C., Bichlmeier, M., Pabst, E., Mackey, D., Parker, J. E., and Vlot, A. C. 2014. Contrasting roles of the apoplastic aspartyl protease APOPLASTIC, ENHANCED DISEASE SUSCEPTIBILITY1-DEPENDENT1 and LEGUME LECTIN-LIKE PROTEIN1 in Arabidopsis systemic acquired resistance. Plant Physiol. 165:791-809.

Büschges, R., Hollricher, K., Panstruga, R., Simons, G., Wolter, M., Frijters, A., van Daelen, R., van der Lee, T., Diergaarde, P., Groenendijk, J., Töpsch, S., Vos, P., Salamini, F., and Schulze-Lefert, P. 1997. The barley Mlo gene: A novel control element of plant pathogen resistance. Cell 88:695-705.

Chen, Y.-C., Holmes, E. C., Rajniak, J., Kim, J.-G., Tang, S., Fischer, C. R., Mudgett, M. B., and Sattely, E. S. 2018. $N$-hydroxy-pipecolic acid is a mobile metabolite that induces systemic disease resistance in Arabidopsis. Proc. Natl. Acad. Sci. U.S.A. 115:E4920-E4929.

Conrath, U., Beckers, G. J. M., Langenbach, C. J. G., and Jaskiewicz, M. R. 2015. Priming for enhanced defense. Annu. Rev. Phytopathol. 53:97-119.

Cui, H., Tsuda, K., and Parker, J. E. 2015. Effector-triggered immunity: From pathogen perception to robust defense. Annu. Rev. Plant Biol. 66: 487-511.

Delledonne, M., Zeier, J., Marocco, A., and Lamb, C. 2001. Signal interactions between nitric oxide and reactive oxygen intermediates in the plant hypersensitive disease resistance response. Proc. Natl. Acad. Sci. U.S.A. 98:13454-13459.

Delventhal, R., Rajaraman, J., Stefanato, F. L., Rehman, S., Aghnoum, R., McGrann, G. R. D., Bolger, M., Usadel, B., Hedley, P. E., Boyd, L., Niks, R. E., Schweizer, P., and Schaffrath, U. 2017. A comparative analysis of nonhost resistance across the two Triticeae crop species wheat and barley. BMC Plant Biol. 17:232.

Dey, S., Wenig, M., Langen, G., Sharma, S., Kugler, K. G., Knappe, C., Hause, B., Bichlmeier, M., Babaeizad, V., Imani, J., Janzik, I., Stempfl, T., Hückelhoven, R., Kogel, K.-H., Mayer, K. F. X., and Vlot, A. C. 2014. Bacteria-triggered systemic immunity in barley is associated with WRKY and ETHYLENE RESPONSIVE FACTORs but not with salicylic acid. Plant Physiol. 166:2133-2151.

Ding, P., Rekhter, D., Ding, Y., Feussner, K., Busta, L., Haroth, S., Xu, S., Li, X., Jetter, R., Feussner, I., and Zhang, Y. 2016. Characterization of a pipecolic acid biosynthesis pathway required for systemic acquired resistance. Plant Cell 28:2603-2615.

Fu, Z. Q., and Dong, X. 2013. Systemic acquired resistance: Turning local infection into global defense. Annu. Rev. Plant Biol. 64:839-863.

Gao, Q.-M., Zhu, S., Kachroo, P., and Kachroo, A. 2015. Signal regulators of systemic acquired resistance. Front. Plant Sci. 6:228.

Garcia-Seco, D., Chiapello, M., Bracale, M., Pesce, C., Bagnaresi, P., Dubois, E., Moulin, L., Vannini, C., and Koebnik, R. 2017. Transcriptome and proteome analysis reveal new insight into proximal and distal responses of wheat to foliar infection by Xanthomonas translucens. Sci. Rep. 7:10157.

Hartmann, M., Kim, D., Bernsdorff, F., Ajami-Rashidi, Z., Scholten, N., Schreiber, S., Zeier, T., Schuck, S., Reichel-Deland, V., and Zeier, J.
2017. Biochemical principles and functional aspects of pipecolic acid biosynthesis in plant immunity. Plant Physiol. 174:124-153.

Hartmann, M., and Zeier, J. 2018. L-Lys metabolism to $N$-hydroxypipecolic acid: An integral immune-activating pathway in plants. Plant J. 96:5-21.

Hartmann, M., Zeier, T., Bernsdorff, F., Reichel-Deland, V., Kim, D., Hohmann, M., Scholten, N., Schuck, S., Bräutigam, A., Hölzel, T., Ganter, C., and Zeier, J. 2018. Flavin monooxygenase-generated $N$ hydroxypipecolic acid is a critical element of plant systemic immunity. Cell 173:456-469.e16.

Hückelhoven, R., Fodor, J., Preis, C., and Kogel, K.-H. 1999. Hypersensitive cell death and papilla formation in barley attacked by the powdery mildew fungus are associated with hydrogen peroxide but not with salicylic acid accumulation. Plant Physiol. 119:1251-1260.

Hückelhoven, R., and Kogel, K.-H. 1998. Tissue-specific superoxide generation at interaction sites in resistant and susceptible near-isogenic barley lines attacked by the powdery mildew fungus (Erysiphe graminis f. sp. hordei). Mol. Plant-Microbe Interact. 11:292-300.

Jain, S. K., Langen, G., Hess, W., Börner, T., Hückelhoven, R., and Kogel, K.-H. 2004. The white barley mutant albostrians shows enhanced resistance to the biotroph Blumeria graminis f. sp. hordei. Mol. PlantMicrobe Interact. 17:374-382.

Jansen, C., von Wettstein, D., Schäfer, W., Kogel, K.-H., Felk, A., and Maier, F. J. 2005. Infection patterns in barley and wheat spikes inoculated with wild-type and trichodiene synthase gene disrupted Fusarium graminearum. Proc. Natl. Acad. Sci. U.S.A. 102:16892-16897.

Jones, J. D. G., and Dangl, J. L. 2006. The plant immune system. Nature 444:323-329.

Jung, H. W., Tschaplinski, T. J., Wang, L., Glazebrook, J., and Greenberg, J. T. 2009. Priming in systemic plant immunity. Science 324:89-91.

Kiyota, E., Pena, I. A., and Arruda, P. 2015. The saccharopine pathway in seed development and stress response of maize. Plant Cell Environ. 38: 2450-2461

Klessig, D. F., Choi, H. W., and Dempsey, D. A. 2018. Systemic acquired resistance and salicylic acid: Past, present, and future. Mol. PlantMicrobe Interact. 31:871-888.

Kogel, K.-H., Beckhove, U., Dreschers, J., Münch, S., and Rommé, Y. 1994. Acquired resistance in barley (the resistance mechanism induced by 2,6-dichloroisonicotinic acid is a phenocopy of a genetically based mechanism governing race-specific powdery mildew resistance). Plant Physiol. 106:1269-1277.

Kogel, K. H., Ortel, B., Jarosch, B., Atzorn, R., Schiffer, R., and Wasternack, C. 1995. Resistance in barley against the powdery mildew fungus (Erysiphe graminis f.sp. hordei) is not associated with enhanced levels of endogenous jasmonates. Eur. J. Plant Pathol. 101:319-332.

Künstler, A., Bacsó, R., Albert, R., Barna, B., Király, Z., Hafez, Y. M., Fodor, J., Schwarczinger, I., and Király, L. 2018. Superoxide $\left(\mathrm{O}_{2}^{{ }^{-}}\right)$ accumulation contributes to symptomless (type I) nonhost resistance of plants to biotrophic pathogens. Plant Physiol. Biochem. 128:115-125.

Laflamme, B., Middleton, M., Lo, T., Desveaux, D., and Guttman, D. S. 2016. Image-based quantification of plant immunity and disease. Mol. Plant-Microbe Interact. 29:919-924.

Lenk, M., Wenig, M., Mengel, F., Häußler, F., Vlot, A., Lenk, M., Wenig, M., Mengel, F., Häußler, F., and Vlot, A. C. 2018. Arabidopsis thaliana immunity-related compounds modulate disease susceptibility in barley. Agronomy (Basel) 8:142.

Liu, Z., Ellwood, S. R., Oliver, R. P., and Friesen, T. L. 2011. Pyrenophora teres: Profile of an increasingly damaging barley pathogen. Mol. Plant Pathol. 12:1-19.

Maldonado, A. M., Doerner, P., Dixon, R. A., Lamb, C. J., and Cameron, R. K. 2002. A putative lipid transfer protein involved in systemic resistance signalling in Arabidopsis. Nature 419:399-403.

Mauch-Mani, B., Baccelli, I., Luna, E., and Flors, V. 2017. Defense priming: An adaptive part of induced resistance. Annu. Rev. Plant Biol. 68:485-512.

Mishina, T. E., and Zeier, J. 2006. The Arabidopsis flavin-dependent monooxygenase FMO1 is an essential component of biologically induced systemic acquired resistance. Plant Physiol. 141:1666-1675.

Møller, B. L. 1974. Lysine Biosynthesis in Barley (Hordeum vulgare L.). Plant Physiol. 54:638-643.

Návarová, H., Bernsdorff, F., Döring, A.-C., and Zeier, J. 2012. Pipecolic acid, an endogenous mediator of defense amplification and priming, is a critical regulator of inducible plant immunity. Plant Cell 24: 5123-5141.

Pálfi, G., and Dézsi, L. 1968. Pipecolic acid as an indicator of abnormal protein metabolism in diseased plants. Plant Soil 29:285-291.

Pieterse, C. M. J., Van der Does, D., Zamioudis, C., Leon-Reyes, A., and Van Wees, S. C. M. 2012. Hormonal modulation of plant immunity. Annu. Rev. Cell Dev. Biol. 28:489-521. 
Riedlmeier, M., Ghirardo, A., Wenig, M., Knappe, C., Koch, K., Georgii, E., Dey, S., Parker, J. E., Schnitzler, J.-P., and Vlot, A. C. 2017. Monoterpenes support systemic acquired resistance within and between plants. Plant Cell 29:1440-1459.

Scheler, C., Durner, J., and Astier, J. 2013. Nitric oxide and reactive oxygen species in plant biotic interactions. Curr. Opin. Plant Biol. 16: 534-539.

Schindelin, J., Arganda-Carreras, I., Frise, E., Kaynig, V., Longair, M., Pietzsch, T., Preibisch, S., Rueden, C., Saalfeld, S., Schmid, B., Tinevez, J. Y., White, D. J., Hartenstein, V., Eliceiri, K., Tomancak, P., and Cardona, A. 2012. Fiji: An open-source platform for biological-image analysis. Nat. Methods 9:676-682.

Shah, J., Chaturvedi, R., Chowdhury, Z., Venables, B., and Petros, R. A. 2014. Signaling by small metabolites in systemic acquired resistance. Plant J. 79:645-658.

Sharma, R., De Vleesschauwer, D., Sharma, M. K., and Ronald, P. C. 2013. Recent advances in dissecting stress-regulatory crosstalk in rice. Mol. Plant 6:250-260.

Song, J. T., Lu, H., McDowell, J. M., and Greenberg, J. T. 2004. A key role for $A L D 1$ in activation of local and systemic defenses in Arabidopsis. Plant J. 40:200-212.

Spoel, S. H., and Dong, X. 2012. How do plants achieve immunity? Defence without specialized immune cells. Nat. Rev. Immunol. 12: 89-100.

Spoel, S. H., Johnson, J. S., and Dong, X. 2007. Regulation of tradeoffs between plant defenses against pathogens with different lifestyles. Proc. Natl. Acad. Sci. U.S.A. 104:18842-18847.

Thordal-Christensen, H., Gregersen, P. L., and Collinge, D. B. 2000. The barley/Blumeria (Syn. Erysiphe) graminis interaction. Pages 77-100 in: Mechanisms of Resistance to Plant Diseases. Springer Netherlands, Dordrecht, The Netherlands.

Trujillo, M., Kogel, K. H., and Hückelhoven, R. 2004. Superoxide and hydrogen peroxide play different roles in the nonhost interaction of barley and wheat with inappropriate formae speciales of Blumeria graminis. Mol. Plant-Microbe Interact. 17:304-312.

Vernooij, B., Friedrich, L., Morse, A., Reist, R., Kolditz-Jawhar, R., Ward, E., Uknes, S., Kessmann, H., and Ryals, J. 1994. Salicylic acid is not the translocated signal responsible for inducing systemic acquired resistance but is required in signal transduction. Plant Cell 6:959-965.

Vlot, A. C., Dempsey, D. A., and Klessig, D. F. 2009. Salicylic acid, a multifaceted hormone to combat disease. Annu. Rev. Phytopathol. 47: 177-206.
Vlot, A. C., Pabst, E., and Riedlmeier, M. 2017. Systemic Signalling in Plant Defence. eLS. John Wiley Sons, Ltd., Chichester, U.K. DOI: 10.1002/9780470015902.a0001322.pub3

Wang, C., El-Shetehy, M., Shine, M. B., Yu, K., Navarre, D., Wendehenne, D., Kachroo, A., and Kachroo, P. 2014. Free radicals mediate systemic acquired resistance. Cell Reports 7:348-355.

Wang, C., Liu, R., Lim, G.-H., Lorenzo, L. De, Yu, K., Zhang, K., Hunt, A. G., Kachroo, A., and Kachroo, P. 2018. Pipecolic acid confers systemic immunity by regulating free radicals. Sci. Adv. 4:eaar4509.

Wendehenne, D., Gao, Q. M., Kachroo, A., and Kachroo, P. 2014. Free radical-mediated systemic immunity in plants. Curr. Opin. Plant Biol. 20:127-134.

Wittek, F., Hoffmann, T., Kanawati, B., Bichlmeier, M., Knappe, C., Wenig, M., Schmitt-Kopplin, P., Parker, J. E., Schwab, W., and Vlot, A. C. 2014. Arabidopsis ENHANCED DISEASE SUSCEPTIBILITY1 promotes systemic acquired resistance via azelaic acid and its precursor 9-oxo nonanoic acid. J. Exp. Bot. 65:5919-5931.

Wittek, F., Kanawati, B., Wenig, M., Hoffmann, T., Franz-Oberdorf, K., Schwab, W., Schmitt-Kopplin, P., and Vlot, A. C. 2015. Folic acid induces salicylic acid-dependent immunity in Arabidopsis and enhances susceptibility to Alternaria brassicicola. Mol. Plant Pathol. 16:616-622.

Wu, Y., Yi, G., Peng, X., Huang, B., Liu, E., and Zhang, J. 2013. Systemic acquired resistance in Cavendish banana induced by infection with an incompatible strain of Fusarium oxysporum f. sp. cubense. J. Plant Physiol. 170:1039-1046.

Yang, Y., Zhao, J., Liu, P., Xing, H., Li, C., Wei, G., and Kang, Z. 2013. Glycerol-3-phosphate metabolism in wheat contributes to systemic acquired resistance against Puccinia striiformis f. sp. tritici. PLoS One 8: e81756.

Yu, K., Soares, J. M., Mandal, M. K., Wang, C., Chanda, B., Gifford, A. N., Fowler, J. S., Navarre, D., Kachroo, A., and Kachroo, P. 2013. A feedback regulatory loop between G3P and lipid transfer proteins DIR1 and AZI1 mediates azelaic-acid-induced systemic immunity. Cell Reports 3:1266-1278.

Zeier, J. 2013. New insights into the regulation of plant immunity by amino acid metabolic pathways. Plant Cell Environ. 36:2085-2103.

Zipfel, C. 2014. Plant pattern-recognition receptors. Trends Immunol. 35: 345-351.

Zoeller, M., Stingl, N., Krischke, M., Fekete, A., Waller, F., Berger, S., and Mueller, M. J. 2012. Lipid profiling of the Arabidopsis hypersensitive response reveals specific lipid peroxidation and fragmentation processes: Biogenesis of pimelic and azelaic acid. Plant Physiol. 160:365-378. 